\title{
Classification of Management Decision-Making Methods in Economics
}

\author{
Elena Galkina $^{1 *}$ \\ ${ }^{I}$ The Federal State Budgetary Educational Establishment of Higher Education «The Orel State University of \\ Economics and Trade», Russia \\ *Email: gev578@mail.ru
}

\begin{abstract}
The article presents the main methods of economics decision-making. The emphasis in work is made on the classification of such methods to describe the specifics of each group of methods using for different primary conditions of decision-making. The basis of the proposed approach to the classification of methods is, firstly, the relationship with the target indicator of the work of an economic entity in a market economy (profit, net cash flows), and secondly, the applicability of the method for modelling a generalized criterion for the clear choice of the optimal management alternative (depending on the urgency of the decision and the degree of certainty of the initial information). For each group of methods, the economic content is shown, and the basic situations in which the methods could be applied are given. The classification of methods reflects the algorithm for enumerating them to select the most suitable one under certain conditions, reflected in this classification. Model calculations illustrate methods.
\end{abstract}

Keywords: Criterion, Method, Management, Assessment, Managing.

\section{INTRODUCTION}

In the theory and practice of management, including the management of the economy, the main task is to select the optimal management decision. In general, making such a decision comes down to assessing the target criterion for each alternative and choosing the alternative for which the value of the target criterion is better. The variety of management tasks requires the development of methods and techniques for substantiating management actions, which should consider the specifics of various management tasks. At the same time, the methods can be combined into classification groups by the logic of the deployment of the problem solution.

The classification of decision-making methods in scientific literature is considered from different points of view. So, Bushin G.V. focused his attention on combining solutions based on two classification criteria - urgency (strategic decisions) and type of activity (hotel business) [1]. Pashkovsky M.Yu. studied the industrial aspect - making industrial management decisions [2].
Author Koltakova T.V. paid attention to the peculiarities of non-formalized and formalized methods of obtaining decisions [3]. Chuiko N.S., Gavrish E.S. briefly characterize the decision-making methods [4]. Researcher Tebekin A.V. gives a classification of decision-making methods in management according to various classification criteria [5]. Authors Tebekin A.V., Tebekin P.A. focused on the relationship between decision-making methods and performance indicators [6].

The decision-making topic is broad, so many authors have focused on the study of the specificity of individual management methods and their improvement. Thus, Isaev D.V. studied decision-making based on a combination of management accounting and an expert approach [7].

Foreign authors are actively using statistical, mathematical methods as tools for substantiating management decisions. In particular, a group of authors consisting of Gupta D., Pratama M., Ma Z., Li J., Prasad M. studied forecasting financial time-series using 
double support vector regression [8]. The work of researchers Yang C., Liu H., McLoone S., Chen C L P., Wu X. [9] is studied the reducing of variable accuracy in complex knowledge systems. Bunting R. F Jr, Siegal D. focused on developing risk management dashboards [10].

Considering risk management, researchers Bunting R. F Jr, Siegal D. pay attention to the need for a comprehensive application of different methods: "Using a comprehensive approach consisting of quality measures, risk measures, and measures that are less amenable to classification would be the best approach" [10]. Yang C., Liu H., McLoone S., Chen C L P., Wu X. note the importance of collecting a large and varied amount of data: "A comprehensive knowledge system reveals the intangible insights hidden in an information system by integrating information from multiple data sources in a synthetical manner"2 [9]. However, the essence of making a management decision is to choose an option from several alternative options. Therefore, with all the variety of initial information available to the manager, a single criterion for selecting the optimal solution is required, which may be different for different situations.

\section{RESEARCH METHODOLOGY}

The purpose of this work is to generalize and group the methods for decision-making of an economic nature to highlight the conditions for using each group of methods, depending on the fundamental conditions for decision-making (urgency and certainty of data). The basis of the proposed approach to the classification of methods is the connection with the target indicator of the work of an economic entity in a market economy (profit, net cash flows), as well as the applicability for modelling a generalized criterion for the unambiguous choice of the optimal management alternative.

The research stages include grouping decisionmaking methods according to hierarchical levels of classification, highlighting the conditions for using each group of methods, modelling the sequence of selection of methods for decision-making depending on the period for which the decision applies and the degree of certainty of the initial data, and also testing the model on empirical data.

\footnotetext{
${ }^{1}$ Quoted as per original. Translation: "Using an integrated approach consisting of quality indicators, risk indicators and indicators that are less amenable to classification would be the best approach".

${ }^{2}$ Quoted as per original. Translation: "An integrated knowledge system reveals the intangible ideas hidden in the information system through the synthetic integration of information from various data sources".
}

The methods used include both general scientific methods (analysis and synthesis, abstraction and concretization, modelling) and special methods (grouping, arithmetic methods, methods of probability analysis).

Model numerical values were used as analytical data.

\section{RESEARCH RESULT}

The classification of methods for management decision-making in the economy is shown in figure 1.

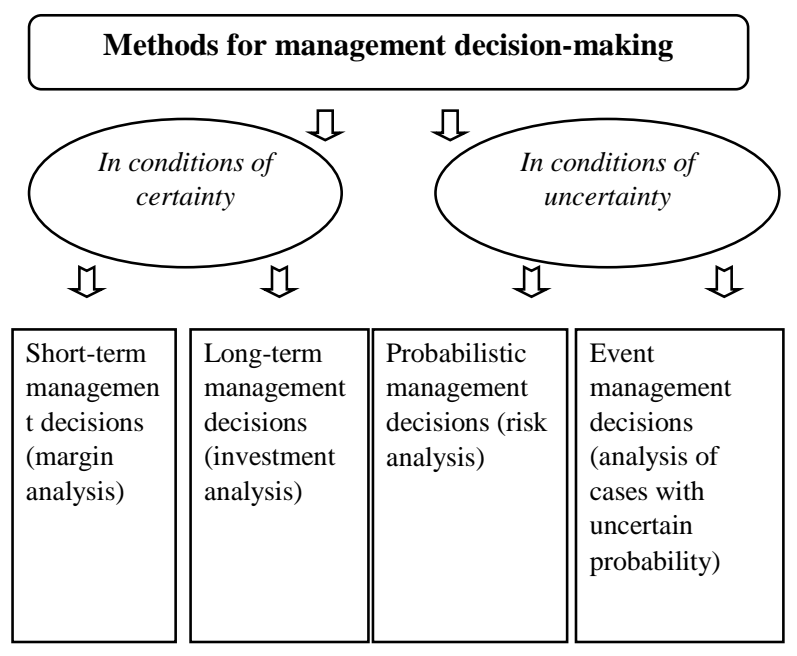

Figure 1 Classification of methods of management decision-making in economics.

This classification combines several criteria:

1) criteria of the management decision-making conditions certainty. If all significant (essential or relevant) parameters of the management task are known, then the manager acts in conditions of certainty, if not all, then in conditions of uncertainty;

2) to select a method for making decisions in conditions of certainty, the criteria of the decisionmaking urgency is used. It is determined by the degree of stability of the conditions in which the management decision is made and implemented. The decision is classified as short-term if the conditions are stable (constant) and classified as long-term if the conditions are unstable (variable). The constancy of the conditions is associated with the period for making a decision, since the more time passes from the moment of the emergence of the management task and until the moment of its solution, the greater the possibility of various changes in the significant parameters of the decision;

3) to select a decision-making method in conditions of uncertainty, the information completeness criteria are used. It is related to the availability of data on the 
occurrence of conditions in the external and internal decision-making environment. If there is complete information about the frequencies (probabilities) of events significant for decision-making, probabilistic decision-making methods, which assess risks and chances as significant indicators weighted by their frequencies, are used. If there is incomplete information about the probabilities, methods of individual events analysis, which combines the methods of other classification decision groups applicable in specific conditions, are used.

In a market economy, the primary benchmark for the effectiveness of management decision is the growth of profits (or net cash flows) of the company. Typical short-term methods are focused on maximizing profit (since accounting methods usually do not change for a short period, and control allows to ensure the correctness of calculations). Typical long-term methods are focused on maximizing cash flows (due to the assumption of the instability of accounting, and income and expenses control methods). However, in both shortterm and long-term management, it is possible to use two approaches, which should be specified in the description of the methodology used to justify a specific decision.

In economics, profit and net cash flows are the basic criteria for the effectiveness of management decisions in conditions of certainty and uncertainty. Based on them, the aggregated indicators can be modelled for macroeconomic analysis.

The specifics of each group of methods are below mentioned.

Management decisions in conditions of certainty are made based on calculating the exact values of the criteria. Short-term decisions usually use actual data, for example, current prices, real scopes of supply and demand, etc. Long-term management decisions use forecast data, which are modelled using reasonable assumptions (proposed for the conclusion of contracts that will enter into force in the future already adopted laws, etc.).

Margin analysis is based on the application of the formula for short-term profit per product - formula (1):

$$
P R=P * Q-V C * Q-F C,
$$

where:

$P R$ - profit from the sale of product,

$P$ - the product price,

$Q$ - the product quantity,

$V C$ - variable cost rate (variable cost per item),

$F C$ - fixed costs.
The classification of expenses is based on their separation in the short term into constant (not dependent on the volume of production and sales) and variable (depending on the volume of production and sales). In the long-term all costs are variable. The scale base is the volume of production and sales (interval of volumes), in which fixed costs do not change. In the medium-term, fixed costs change step-wise from one level of the scale base to another, which also allows the use of margin analysis.

Short-term decisions include decisions about changing the volume of production and sales of goods (about accepting an additional order for goods, about choosing from production options or purchasing components, etc.). Within a broad base, fixed costs are unchanged and may not be considered when making product decisions. Thus, if the price at which the client offers to sell him an additional quantity of goods $(P)$ is higher than the rate of variable costs $(V C)$, such an additional order within the current scale base will increase the overall financial result of the company (by the amount $P^{*} Q-V C^{*} Q$ ), and vice versa.

Long-term management decisions (economic - for investment projects) in conditions of certainty are based on the fact that over a long time interval money changes its purchasing power. Therefore, to make decisions at the current moment, all financial flows are reduced to their current value, that is, they are discounted. The main criterion for making long-term economic decisions is the net present value $(N P V)$ - formula (2):

$$
N P V=\sum_{i=1}^{n} \frac{F V_{i}}{(1+r)^{i}}-C
$$

where:

$F V$ - the investment project's forecast value of the net cash flows, in monetary units of future periods (before discounting),

$r$ - discount factor, including the expected rate of return on the investment project, adjusted for the average expected inflation rate for the investment project period,

$C$ - the initial investment of project participants,

$i$ - unit number of the investment project implementation period (usually a year),

$n$ - number of investment project implementation periods.

The project is assessed as acceptable if $N P V$ is not less than zero (the more, the better for the investor). The $N P V$ formula can be modified depending on the management problem. Thus, in different periods, different discount factors can be used, or if investments are attracted during the life of the project, then they can be discounted by the inflation rate. In addition to $N P V$, 
indicators derived from it are also often considered, for example, the internal rate of return (the value of the discount coefficient $r$, at which $N P V$ is zero), payback period, etc.

In complex problems, there can be several criteria for evaluating each alternative (option) of solving the problem. In economic decisions, this approach is used when the value of the financial criterion for all alternatives is the same (for example, equal marginal profit for an additional order from different buyers, the equal net present value of different investment projects). Then, based on these particular criteria, a single, generalized criterion is modelled, since it is necessary to rank the options to choose the best one. When modelling a generalized criterion, it is necessary to evaluate the significance of individual criteria, solution parameters. This technique belongs to the group of decision-making in conditions of certainty because the method for assigning significance levels of parameters is developed and applied by the manager. For example, when buying one building out of several, put up for sale at the same price, the following criteria can be distinguished as essential: the location of the object (the significance of the criterion is $50 \%$ or 0.5 in a fraction of a unit), the number of floors (the significance is $20 \%$, or 0,2 ), novelty or the presence of repairs (significance $30 \%$, or 0.3 ). The generalized criterion will be equal to the sum of the products of the estimates of each parameter and its significance. Suppose there are two buildings with criteria scores in points (according to the principle "higher points - better score"), respectively, 3$2-1$ and 2-1-2. Then the generalized criterion will be for the first building $2.2(0.5 * 3+0.2 * 2+0.3 * 1)$, for the second building $1.8(0.5 * 2+0.2 * 1+0.3 * 2)$, and the first building will be the best according to this criterion.

Probabilistic methods of making management decisions are based on the assumption that the manager has reliable information about the frequency of distribution of external (for the enterprise) and internal conditions. All external conditions form a complete set of events. And all internal conditions form a complete set of events. Based on these frequencies, the probability (in percent or fractions of a unit) of the occurrence of each external (internal) condition is calculated. Then, based on these data, the probability of a joint occurrence (combination) of each external and internal condition is determined - as the product of their probabilities (assuming the independence of these conditions). The content of the conditions is determined by a specific task.

For each combination of external and internal conditions, a target criterion for the effectiveness of management decisions (profit, etc.) is calculated before adjusting for uncertainty, which is then multiplied by the probability of this combination (in fractions of a unit), which gives a probability-weighted criterion. A model example of weighted criteria is presented in Table 1. In the example, the weighted profit will be when external condition 1 occurs - 0.54 million rubles, external condition 2 - 1.02 million rubles, internal condition 1 - 1.26 million rubles, internal condition 2 0.3 million rubles. The profit assession for each combination is presented at the intersection of the corresponding conditions row and column. The highest probabilistically estimated profit will be brought by the ratio of internal condition 1 and external condition 2 (0.84 million rubles).

The accuracy of the analysis depends on the reliability of the information and the parameters controllability.

Analysis in a situation with an unknown probability of events outcome is based on the reduction of probabilistic problems - that is, the exclusion of those model parameters about which there is no information.

Table 1. A model example of weighted management decision-making criteria

\begin{tabular}{|c|c|c|c|}
\hline Indicators & $\begin{array}{l}\text { External condition } 1 \text {, } \\
\text { probability } 0.4\end{array}$ & $\begin{array}{l}\text { External condition } 2 \text {, } \\
\text { probability } 0.6\end{array}$ & $\begin{array}{c}\text { Internal Weighted Criterion, } \\
\text { Sum by Row }\end{array}$ \\
\hline Internal condition 1 , probability 0.7 & $\begin{array}{l}\text { Profit } 1.5 \text { million rubles * } 0.7 \\
* 0.4=0.42 \text { million rubles }\end{array}$ & $\begin{array}{l}\text { Profit } 2 \text { million rubles * } 0.7 \\
* 0.6=0.84 \text { million rubles }\end{array}$ & 71.26 millic \\
\hline Internal condition 2, probability 0.3 & $\begin{array}{l}\text { Profit } 1 \text { million rubles }{ }^{*} 0.3 \\
0.4=0.12 \text { million rubles }\end{array}$ & $\begin{array}{l}\text { Profit } 1 \text { million rubles }{ }^{*} 0.3 \\
\star 0.6=0.18 \text { million rubles }\end{array}$ & 30.3 million rubles \\
\hline $\begin{array}{l}\text { The weighted criterion by external } \\
\text { conditions, Sum by Column }\end{array}$ & 0.54 million rubles & 1.02 million rubles & 1.56 million rubles. \\
\hline
\end{tabular}


Table 2. A model example of weighted management decision-making criteria with incomplete information on the distribution of event probabilities

\begin{tabular}{|c|c|c|c|}
\hline Indicators & $\begin{array}{c}\text { External condition 1, } \\
\text { probability is unknown and } \\
\text { taken equal to } 0.5\end{array}$ & $\begin{array}{c}\text { External condition } 2 \text {, the } \\
\text { probability is unknown and } \\
\text { taken equal to } 0.5\end{array}$ & $\begin{array}{l}\text { Weighted Criterion for } \\
\text { Internal conditions }\end{array}$ \\
\hline Internal condition 1 , probability 0.7 & $\begin{array}{c}\text { Profit } 1.5 \text { million rubles }{ }^{*} 0.7 \\
{ }^{*} 0.5=0.525 \text { million rubles }\end{array}$ & $\begin{array}{c}\text { Profit } 2 \text { million rubles * } 0.7 \\
* 0.5=0.7 \text { million rubles }\end{array}$ & 1.225 million rubles \\
\hline Internal condition 2 , probability 0.3 & $\begin{array}{c}\text { Profit } 1 \text { million rubles * } 0.3 \text { * } \\
0.5=0.15 \text { million rubles }\end{array}$ & $\begin{array}{l}\text { Profit } 1 \text { million rubles * } 0.3 \\
{ }^{*} 0.5=0.15 \text { million rubles }\end{array}$ & 0.3 million rubles \\
\hline $\begin{array}{l}\text { Weighted criterion for External } \\
\text { conditions }\end{array}$ & 0,675 million rubles & 0,85 million rubles & 1,525 million rubles \\
\hline
\end{tabular}

In particular, if the frequencies of internal conditions are known, but the set of external conditions is unknown, such conditions are assumed to be equally probable (that is, the probability of each is equal to one or $100 \%$ divided by the number of conditions). If we use the data of the model example (table 1), then with an unknown probability of external conditions, the problem will look as shown in table 2 .

In modern control theory, the approaches to the theory of fuzzy sets are also applicable. During choosing from several alternatives, fuzziness occurs in the case of a collective way of evaluating data. Then different persons (experts) can give different assessments, due to which the fuzziness of the value of each criterion or probability is formed. However, since the decision must be made unambiguously, these estimates, which form the variation series, can be reduced to a clear estimate by averaging the values.
Table 3 shows a model example of translating a fuzzy estimate of the probability of the onset of external conditions into a clear estimate. To select a management decision according to the model described in Table 1, the arithmetic mean of the probability of each external condition from table 3 will be used.

\section{CONCLUSION}

The presented iterations of choosing a model for making managerial decisions in general have a high level of generalization and applicable to various economic problems. The task description can be even more concise than the datasets presented above. Such a situation arises when a set of external or internal conditions is unknown (there is a set of only internal conditions and external ones are unknown, or there is a set of external conditions and alternatives to one internal condition are unknown). If there is no reliable

Table 3. A model example of translating a fuzzy assessment of the probabilities of external conditions into a clear assessment

\begin{tabular}{|l|c|c|c|}
\hline \multicolumn{1}{|c|}{ Probability assessment } & External condition 1 & External condition 2 & $\begin{array}{c}\text { The sum of the } \\
\text { probabilities of the } \\
\text { complete group of events }\end{array}$ \\
\hline Expert 1 & 0.4 & 0.6 & 1 \\
\hline Expert 2 & 0.6 & 0.4 & 1 \\
\hline Expert 3 & 0.2 & 0.8 & 1 \\
\hline $\begin{array}{l}\text { Arithmetic average of probability } \\
\text { assessment }\end{array}$ & 0.4 & 0.6 & 1 \\
\hline
\end{tabular}


information about the alternatives, the analysis becomes predictive and the manager makes assumptions about the expected values of his problem model. If there is no reliable information about the alternatives, then the analysis becomes predictive and the manager makes assumptions about the expected values of his problem model.

\section{REFERENCES}

[1] G.V. Bushin, Classification of methods for assessing the effectiveness of management decisions in strategic planning in the hotel business, Bulletin of the National Academy of Tourism 1(17) (2011) 31-34.

[2] M.Yu. Pashkovsky, Classification of methods for making production management decisions, In the collection: Actual problems of management and economics in Russia and abroad. Collection of scientific papers on the results of the international scientific and practical conference, 2015, pp. 4548 .

[3] Koltakova, T.V. Classification of methods for the development of management decisions-making, Voronezh Institute of High Technologies Bulletin 2(15) (2015) 128-133.

[4] N.S. Chuiko, E.S. Gavrish, Classification of methods of analysis of management decisions, In the collection: Science, education and innovation. Collection of articles of the international scientific and practical conference, 2016, pp. 285-286.

[5] A.V. Tebekin, Classification of methods of making management decisions in management by areas of application, Bulletin of Moscow University named by S.Yu. Vitte. Episode 1: Economics and Management 4(19) (2016) 57-63. DOI: https://doi.org/10.21777/2307-6135-2016-4-57-63

[6] A.V. Tebekin, P.A. Tebekin, Classification of methods for making management decisions based on optimization of performance indicators, Management Research Journal Vol. 4 Iss. 4 (2018) 13-24.

[7] D.V. Isaev, Decision making using a combination of management accounting and an expert approach, Business Informatics Issue 4 (2016) 70-80. DOI: https://doi.org/ 10.17323/1998-0663.2016.4.70.78

[8] D. Gupta, M. Pratama, Z. Ma, J. Li, M. Prasad, Financial time series forecasting using twin support vector regression, PLoS ONE Vol. 14 Iss. 3 (2019) e0211402. DOI: https://doi.org/ 10.1371/journal.pone.0211402

[9] C. Yang, H. Liu, S. McLoone, C.L.P. Chen, X. $\mathrm{Wu}$, A Novel Variable Precision Reduction
Approach to Comprehensive Knowledge Systems, IEEE transactions on cybernetics Vol. 48 Issue 2 (2018) 661-674. DOI: https://doi.org/10.1109/TCYB.2017.2648824

[10] R.F. Bunting, D.Jr. Siegal,. Developing risk management dashboards using risk and quality measures: A visual best practices approach, Journal of healthcare risk management: the journal of the American Society for Healthcare Risk Management Vol. 37 Iss. 2 (2017) 8-28. DOI: https://doi.org/10.1002/jhrm.21287 